\title{
The Wilderness Library
}

\author{
We gratefully acknowledge the permission \\ granted for publication of this work by the \\ copyright holder(s):
}

(C) 1991 by Journal of Leisure Research 


\title{
The Influence of Past Experience on $\mathrm{W}$ ilderness Choice
}

\author{
Alan E. Watson \\ USDA Forest Service \\ Intermountain Research Station \\ Joseph W. Roggenbuck \\ Virginia Polytechnic \\ Institute and State University \\ Daniel R. Williams \\ Virginia Polytechnic Institute \\ and State University
}

A study of Southern Appalachian backcountry hikers tested the hypothesis that recreationists with high experience levels would have greater differentiation of site attribute values when making recreation choices than would individuals with low experience. Contrary to cognitive development theory. a simulated laboratory choice study found that more experienced subjects employed fewer and broader attribute value categories that did their less experienced counterparts. This surprising finding might be explained by the nature of the judgment task. Cognitive development theory suggests that greater experience leads to greater perceptual distinction along a range of attribute values, but social judgment theory suggests fewer attitudinal or preference distinctions along the range of attribute values with increased involvement with the issue or object. Leisure planners, managers, and programmers must decide what type of judgment they are asking recreationists to make when they attempt to influence choice through provision of information.

KEYWORDS: Backcountry experience, specialization, categorization, specificity of attributes, recreation choice

\section{Introduction}

One of' the important goals of recreation management is to provide a continuing flow of satisfying experiences to the public (McCool, Stankey, \& Clark, 1985). In the past, managers tried to achieve this goal by altering or protecting the resource, providing facilities, providing programs to increase understanding and enjoyment of park resources, or managing people to reduce conflicts and protect health and safety. Recently, however, many have recognized that resources might best be protected and experiences most greatly enhanced by helping people choose the best recreation area to meet their needs (McCool et al., 1985). Given this, recreation plan-

The research resulting in this publication was funded jointly by the USDA Forest Service and Virginia Polytechnic Institute and State University. Data collection and analysis activities occurred at Virginia Polytechnic Institute and State University. Requests for reprints should be sent to the first author at: USDA Forest Service, Intermountain Research Station. Forestry Sciences Laboratory, P.O. Box 8089, Missoula. MT 59807. 
ners, managers, and researchers have become increasingly interested in recreation choice processes.

Conceptual approaches for the study of how recreationists select places to visit can be arranged on a continuum of the extent to which individua preference determines choice. At one end are the approaches that examine the forces outside an individual that govern choice. These approaches emphasize that the availabilitv of attractive recreation sites, distance to alternative recreation sites, availability of transportation and fuel, and cost of fuel or public transportation heavily influence recreation decisions (Lieber, Fesenmaier, \& Bristow, 1989; Peterson, Dwyer \& Darragh, 1983). Toward the middle of the spectrum we find theories that focus on the social factors---friends, families, or club affiliates--that influence recreation decisions (Bultena \& Field, 1980; West. 1982). These theorists argue that social referents influence recreation choice, noting that "our" favorite recreation site may not be the same as "my" favorite site (Clark \& Downing, 1985). At the other end of the spectrum are the theories that focus on how individuals choose from among several options guided by their own preferences (Krumpe \& McLaughlin, 1982; Schreyer \& Beaulieu, 1986; Williams, 1985).

Certainly the environmental and social setting shape recreation choices, but we believe that the very nature of recreation, as an experience characterized by freedom of individual choice, favors theories that emphasize individual decision making. We view recreationists as active-not passiveplayers in the choice process (Knopf, 1983). The purpose of this paper is to examine how experience levels of recreationists influence the way they process and shape information from the environment to make a choice. More specifically, we examine the relationship between past experience and differentiation among attribute categories used in evaluating recreation choice alternatives.

\section{The Cognitire Approach to Recreation Choice}

The individual, cognitive approach to recreation choice recognizes that information from outside the individual is taken in, shaped, reconstructed, and interpreted on the basis of internal models of reality during the process of decision making (Krumpe \& McLaughlin, 1982). To understand recreation choice, one must understand this process. To understand this process, at least four basic questions must be addressed: What environmental stimuli bombarding the individual are attended to and relevant to the choice process? At what level of specificity or abstraction are these stimuli encoded? What characteristics of the individual shape the internal image of the exterior environment? How are the many external stimuli weighted, ordered, combined, and processed to make a decision? (See Krumpe \& McLaughlin, 1982; McCool et al., 1985; Schreyer \& Beaulieu, 1986.)

Recreation researchers have begun to answer some of these questions. For example, attributes of the environmental setting are believed to be the most relevant external stimuli to the choice process. Peterson, Stynes, Rosenthal, and Dwyer (1985) cite consumer theory that contends that the object of choice is not the good itself but rather the attributes possessed by that good. Clark and Stankey (1979) contend that the combination of the physical/biological, social, and managerial attributes of a recreation setting gives that place value as a locale for leisure behavior. Thus, relevant attributes of the environment include not only the natural features, but also human use, users, facilities, and such managerial interventions as rules and regulations (Schreyer, Knopf, \& Williams, 1985). Based on the conceptual work of Clark and Stankey (1979), and Driver, Brown, and their associates (for example, see Brown, Driver, \& McConnell, 1978; Driver \& Brown, 1978; Driver, Brown. Stankey, \& Gregoire, 1987; Manfredo, Driver. \& Brown, 1983), the Recreation Opportunity Spectrum (ROS) land classification system has been developed and adopted extensively throughout the United States. The system is founded on the notion that environmental features or attributes are linked to desirable experiences. The assumption is that recreationists consider and weigh the attributes expressed in the ROS to select sites that promise satisfying experiences.

Recently some have questioned the appropriateness of the individual attributes considered in the ROS system (Williams \& Knopf, 1985). the type of attributes considered (Williams \& Knopf, 1985), the level of abstraction of attributes considered (Schreyer et al., 1985), and the implication that behavioral responses to setting attributes will be consistent across individuals (Schreyer, 1982; Schreyer \& Beaulieu, 1986; Schreyer, Lime, \& Williams, 1984; Williams, 1983). These challenges arise from the view that individuals process information not only on the basis of external stimuli but also on the basis of existing, internal representations of the world. Additionally, these internal representations, or images, evolve in content and complexity as the individuals gain more experience and information about the object or situation under consideration (Williams. 1985). For example, individuals at different levels of experience have been found to define the leisure meanings and desired outcomes of similar recreation settings differently (Schreyer \& Lime, 1984; Schreyer \& Roggenbuck, 1978; Schreyer et al., 1984; Williams, Schreyer \& Knopf, 1989). Thus, in order to predict. understand, and shape recreation choice, we need to know more about the internal person, the current frame of reference from which he or she evaluates settings, how the frame of reference evolves with experience, and how the frame of reference shapes the relevance, importance, and specificity of attributes. More specifically, we need to know how experience level of the recreationist may influence appropriate level of detail of information needed to shape recreation choices.

\section{Past Experience as a Developmental Frame of Reference for Recreation Choice}

Cognitive development theory provides a useful framework for making predictions about the role of past experience on information processing 
and recreation choice (Williams, 1985; Williams et al., 1989). Research based on developmental theory clearly demonstrates that the content and structure of cognitions evolve with development, leading to greater differentiation. complexity, abstraction, and integration of cognitions (Bieri, 1966; Flavell, 1972; Moore, 1979; Scott, 1969). For example, Scott (1969) concluded from review of several studies that increased information tends to increase the differentiation of attributes in a cognitive domain. While a number of operational measures of differentiation have been proposed, consumer choice researchers (Park \& Lessig, 1977, 1981) have generally defined it as the number of distinct levels or values a person perceives along an attribute (e.g., price or usable capacity for microwave ovens). This most closely resembles what Scott (1969) defined as attribute differentiation.

Developmental theory would suggest that as recreationists gain knowledge, through experience, about a given setting or activity, their cognitive representations of that setting would become more complex (Williams, 1985). Their images would become more detailed and organized in more complex ways. As development proceeds, increased differentiation occurs within internal representations, and what was previously seen as an undifferentiated domain now becomes two or more distinct categories within the original domain (Williams, 1983). With the new, more numerous and more complex internal categories, the individual sees the world differently. $\mathrm{He}$ or she interprets, makes sense of, and responds to external stimuli in different ways.

Level of experience thus becomes critical to understanding the choice process. More cognitively advanced recreationists have more internal categories, more complex categories, and more complex relationships among categories through which they interpret and make sense out of the external world. Thus, individuals with little knowledge or experience in a given setting or activity likely make decisions on the basis of information organized at the macrolevel. Experienced recreationists make finer distinctions among similar alternative settings and activities, and therefore need more detailed information.

The limited recreation research to date gives some support to the hypothesis that increasing experience leads to increased specificity and differentiation of recreation environments. Schreyer and Beaulieu (1986) found that recreationists in mountain and desert settings with high experience and commitment levels tended to describe more attributes affecting their site selection decision, more specifically, than did more novice users. These relationships, though significant, were weak. Schreyer (1982). reported that river runners with higher experience levels stated the desired outcomes of their trips more specifically. Finally, Williams (1985) related developmental level of anglers, canoeists, and backpackers to their differentiation of photographs in terms of activity, setting, and social situation attributes and found the hypothesized relationship only in the case of fishing. Thus, type of activity may be a mediating variable. Additional research is necessary to further clarify the relationship between recreationists' level of experience and the specificity of information processed to make recreation choices in a variety of settings or activities.

\section{Research Hypothesis}

Past theory development and some empirical research suggests that (a) recreation choice is influenced by the specificity with which site attributes are defined and considered, and that (b) complexity of attribute definition is shaped by the recreationist's developmental frame of reference that evolves with experience. Some research, however, has failed to find relationships in the hypothesized direction, suggesting a need for further research (Williams, 1985). This study, therefore, addressed the following hypothesis: Recreationists with high experience levels will define attributes more specifically (for example, exhibit more categories on attribute dimensions) than will recreationists at low experience levels.

\section{Methods}

This study examined recreation choice decisions in a controlled laboratory setting. Attributes of hypothetical backcountry areas were presented and the information processing and the final decision were recorded on a microcomputer. The activity selected was overnight backpacking. We chose backpacking because of mixed earlier findings about the site selection behavior of this group (Schreyer \& Beaulieu. 1986; Williams, 1985). and further specified the backpacking to be overnight use so that we might more easily define relevant attributes. The choice context was the selection of a hypothetical backcountry area in the Southern Appalachians; the region where the study took place and about which respondents were familiar. A microcomputer program was designed to present study participants with attribute information on 15 hypothetical backcountry areas, and attributes were described to ensure the entire possible range and combination of values across the areas. Thus, the decision was complex enough to ensure a thoughtful decision making process; there would likely be no one obvious choice for any participant. Any variation in how individuals consider, weigh. and process information to make site choices would likely be demonstrated in our simulation.

\section{Subjects}

Subjects were volunteers who had backpacked or who were planning to take their first backpacking trip. Participants were undergraduate students, members of a university outing club, participants in a wilderness 
leadership training course, faculty and graduate students in forestry and wildlife, and members of the general public.

Participants received a brief overview on the purpose of the study and procedures for operating the microcomputer program. They were then left to their task. Decisions made by the participants were automatically recorded by the microcomputer. The entire task took about 30 minutes.

\section{Variables}

Selecting and describing site attributes. The attributes selected for research were generated from previous studies in spatial cognition, scenic quality, natural hazards, and the social and managerial features of backcountry recreation areas (Brown \& Haas, 1980; Driver \& Knopf, 1977; Feimer, 1983; Haas, Driver \& Brown, 1980; Roggenbuck \& Dawson, 1979). The original list of 33 attributes was pilot tested among 37 university undergraduates. graduates, and faculty who had experience in backpacking to find the 15 items considered to be the most important to area selection (Watson, 1983; see Table 1).

The microcomputer program recorded subjects' responses to varying levels or values for each of the 15 attributes. The possible range of values of some attributes was binary. For example, permits to enter an area are either required or not, campfires are either allowed or not, and campsites are either assigned or not. For other variables, like the probability of finding an isolated campsite, the potential range could have stretched from 0 to $100 \%$. For other variables, like size of area in acres, the, potential range in values was very large. For these attributes with potentially large value ranges. the range was described in 5 to 12 units. For example, miles of trail of an area was divided into nine units: 1-5, 6-10, 11-20, 21-30, 31-40, 41-50, 5175, 76-100, more than 100 miles. Altogether, the 15 attributes had 101 value units across which subjects were asked to make judgments.

Differentiation among attribute categories. Differentiation along attribute dimensions was measured using an approach developed by Park and associates for application in consumer choice modeling (Park, 1978; Park \& Lessig, 1981). Differentiation was determined by asking each subject to indicate how much satisfaction would be derived from each level or value on a given attribute. Subjects rated satisfaction on a seven-point scale ("0" represents maximum dissatisfaction and " 6 " represents maximum satisfaction). According to Park, a category exists whenever two or more levels of an attribute are treated equally. Therefore, if two or more values were indicated as providing the same degree of satisfaction they were treated as one category. For example, the values considered for the "number of people you are likely to encounter during a day of hiking" were $0,1-5,6-10,11$ $20,21-30,31-40.41-50,51-75,76-100$, and more than 100 people. If the subject indicated that encountering 0 and 1-5 people per day both provided maximum satisfaction, the two values were considered as one category. The possible number of categories in the study ranged from 15 to 101 . The
TABLE 1

Important Site Attributes in Backcountry Area Selection

Number of categories used to describe range of

Attribute attribute values

Number of miles of trail between springs

Probability of finding an isolated campsite

Miles of trail in the area

Permits required to enter the area

Campfires allowed in the area

Number of wildlife species you would likely see in the area

Number of people who enter each trailhead per day

Trail configuration

Number of people likely to encounter per day

Campsites assigned in the area

Number of bears seen in the area during last visitor season

Size of the area in acres

Camping at designated sites only in the area

Number of overlooks along trails in the area

Probability of vandalism to your vehicle at the trailhead

higher the total number, the more differentiated was the individual's categorization scheme. The actual range in number of categories in the study was from 43 to 67 , with a mean of 57.1.

Past experience. Previous research employing measures of past experience as a developmental indicator have often used more than one experience variable (Hammitt \& McDonald, 1983; Schreyer et al., 1984). Similarly, in an effort to tap the full meaning of experience in the context of cognitive development, we obtained six measures from our respondents: years of backcountry experience anywhere, average number of backcountry trips per year, number of different backcountry areas visited, years of backcountry experience in the Southern Appalachians, average number of trips per year in the Southern Appalachians, and number of different areas visited in the Southern Appalachians (Table 2).

These various dimensions of past experience have often been combined into a single index of past experience (Beaulieu \& Schreyer, 1985; Hammitt \& McDonald, 1983). We chose not to form a composite index from our six past experience variables for theoretical and psychometric reasons. First, past experience is not a unidimensional construct. Previous studies have shown that various patterns of past experience make a difference in the motivations and preferences of visitors (Schreyer \& Lime, 1984; Schreyer et al., 1984). Moreover, there seems little common sense justification or mathematical propriety in adding across different units of measurement (such as total years and times per year). If experience is 
TABLE 2

Backcountry Experience of Study Participants

\begin{tabular}{lccccc}
\hline \multicolumn{1}{c}{ Variable } & Range & Mean & Median & Mode & Sd \\
\hline $\begin{array}{l}\text { Years of experience anywhere } \\
\text { Average number of trips/year }\end{array}$ & $0-16$ & 8.74 & 8.50 & 5 & 4.31 \\
$\begin{array}{l}\text { Number of different areas visited } \\
\begin{array}{l}\text { Years of experience in the Southern } \\
\text { Appalachians }\end{array}\end{array}$ & $0-25$ & 7.52 & 2.115 & 2 & 2.19 \\
$\begin{array}{l}\text { Average number of trips/year in } \\
\text { the Southern Appalachians }\end{array}$ & $0-15$ & 5.22 & 4.722 & $<1$ & 4.16 \\
$\begin{array}{l}\text { Number of different areas visited in } \\
\text { the Southern Appalachians }\end{array}$ & $0-6$ & 1.72 & 1.50 & $<1$ & 1.62 \\
\hline & $0-20$ & 3.46 & 2.50 & 2 & 3.90 \\
\hline
\end{tabular}

measured as low, medium, and high, then addition or multiplication would be carried out on ordinal data with its consequent problems (Schuster \& Zuuring, 1986). Sometimes weights are assigned to variables when computing the index (Hammitt \& McDonald, 1983), but such weighting is almost always based only on researcher intuition. Finally, the results from a composite index variable are difficult to interpret. The same overall index score can be obtained from a variety of combinations of scores on the items making up the index. Also, with the composite index, it is impossible to determine which dimension of experience. if any, is more relevant.

We therefore treated our six measures of experience as unique dimensions, and treated them as independent variables in tests of our study hypothesis. We felt a one-item measure of each of the dimensions was sufficient because we were simplv asking our respondents to recall number of times, years, or areas they had visited.

\section{Sample Size}

In this study we were not attempting to draw conclusions about a population, so sample size determination based on desired precision in population estimates was irrelevant. Because we had to bring subjects singly to the microcomputer lab, data collection was time consuming. We tried to keep the sample small, while still large enough for theory testing. We monitored the variance in the study's dependent variable, "specificity of categorization," as sample size increased. At 50 subjects the variance had stabilized, and we settled on this number as an acceptable sample size.

\section{Findings}

As an initial test of the study hypothesis, we determined the bivariate correlation (Pearson's) between our six dimensions of experience and degree of differentiation of attribute values (Table 3). Four of the correlations achieved statistical significance: average number of backcountry trips per
TABLE 3

Bivariate Correlations Among Experience Items and Number of Attribute Categories

\begin{tabular}{lcccccc}
\hline & 1 & 2 & 3 & 4 & 5 & 6 \\
\hline I. Number of attribute categories & & & & & & \\
2. Years' backcountry experience & .02 & & & & & \\
3. Average number of backcountry trips/year & $-.18^{*}$ & -.03 & & & & \\
4. Number of backcountry areas visited & .06 & .47 & .19 & & & \\
5. Years' backcountry experience in Southern & $-.18 *$ & .42 & .23 & .11 & & \\
$\quad$ Appalachians & & & & & & \\
6. Average number of backcountry trips/year in & $-.34 * *$ & .07 & .76 & .20 & .54 & \\
$\begin{array}{l}\text { Southern Appalachians } \\
\text { 7. Number of backcountry areas visited in Southern }\end{array}$ & $-.32^{* *}$ & .24 & .31 & .54 & .58 & .56 \\
$\quad$ Appalachians & & & & & & \\
\hline
\end{tabular}

$* p<.10$

$* * p \leq .0$
$v=50$

year and years of backcountry experience in the Southern Appalachians at the $\mathrm{p}<.10$ level, and average number of backcountry trips per year in the Southern Appalachians and number of backcountry areas visited in the Southern Appalachians at the $p=.01$ level. The .10 significance level was chosen rather than the more traditional .01 or .05 level to lower the likelihood of a Type II error, which is an erroneous claim of no relationship. Gregoire and Driver, (1987) have recently urged leisure scientists to be more concerned about the likelihood and Implications of Type II errors. But, contrary to the study hypothesis, all four significant correlations were negative, i.e., the greater the amount of experience, the fewer the number of categories identified among the attributes measured.

To gain a clearer understanding of the role of experience in explaining degree of differentiation of attribute values and to identify the most important dimension(s) of experience, a forward entry regression procedure was performed (Table 4). (Table 3 indicates that the correlations among the experience variables were below .80, which suggests that multicollinearity is not a serious problem (Lewis-Beck, 1980)). A significant relationship was found $(\mathrm{F}=6.42, \boldsymbol{p}=.01)$, but only average number of backcountry trips per year in the Southern Appalachians entered the equation, with a correlation of .34 . The amount of variance explained by the overall regression model was . 10. The negative beta coefficient indicates that the greater the average number of backcountry trips per year in the Southern Appalachians, the fewer the number of attribute value categories.

\section{Discussion}

Contrary to the predictions of Park and Lessig (1981), Schreyer and Beaulieu (1986), and the cognitive complexity literature in general (Bieri, 
TABLE 4

Multiple Regression Summary: Number of Attribute Categories with Six Measures of Past Backcountry Experience

\begin{tabular}{|c|c|c|c|c|c|c|}
\hline Source & $D F$ & SS & $M S$ & $F$ & $R$ & Adjusted $R^{2}$ \\
\hline Regression & $\begin{array}{r}1 \\
48\end{array}$ & $\begin{array}{r}184.20 \\
\end{array}$ & $\begin{array}{r}184.20 \\
28.67\end{array}$ & \multirow[t]{2}{*}{$6.42 *$} & \multirow[t]{2}{*}{.34} & \multirow[t]{2}{*}{.10} \\
\hline Residual & 48 & $1,376.30$ & 28.67 & & & \\
\hline \multicolumn{3}{|c|}{ Variables entered } & \multicolumn{2}{|c|}{$\begin{array}{c}\text { Unstandardized } \\
\text { coefficients }\end{array}$} & $\begin{array}{c}\text { Beta } \\
\text { coefficients }\end{array}$ & $\begin{array}{c}\mathrm{t} \\
\text { values }\end{array}$ \\
\hline \multicolumn{3}{|c|}{$\begin{array}{l}\text { Average number of backcountry trips/ } \\
\text { year in Southern Appalachians }\end{array}$} & \multicolumn{2}{|c|}{-1.20} & -.34 & $-2.54 *$ \\
\hline
\end{tabular}

\section{$p \leqslant .01$}

**The experience variables: years of backcountry experience anywhere, average number of backcountry trips/year, number of backcountry areas visited, years of backcountry experience in the Southern Appalachians. and number of backcountry areas visited in the Southern Appalachians did not enter the equation at the $\mathrm{p}=.10$ significance level.

1966). more experienced participants in our backcountry site selection task evaluated attributes in terms of fewer value categories compared to their less-experienced counterparts. Two methodological explanations might account for these findings, one having to do with sampling and the other with measurement.

First. the sample was limited to 50 subjects that were selected more or less on the basis of convenience. Therefore, our results may simply be an artifact of a unique sample. Another potential limitation with the sample is that subjects were drawn from a university community where participation in wilderness recreation tends to be high (Hendee \& Roggenbuck, 1985). Thus, the sample as a whole was experienced in the use of backcountry, and over the restricted range of experience the effect of little experience may not have manifest itself. But the fact that the sample did produce significant findings, albeit in the opposite direction than hypothesized, tends to lower the plausibility of this explanation.

A more controversial aspect about the methodology we used may be the way we measured experience as an indicator of cognitive development. Given the great diversity of experience dimensions and related indicators, such as specialization, commitment, and familiarity, and the various alternatives for combining the different indicators, the approach we took may not be the most valid. Still, several experience measures were used that have in the past demonstrated a relationship to attribute preference and cognitive complexity, and the literature does not suggest a clearly superior alternative.

We believe it is more likely that competing theoretical models may be contributing to the confusion regarding the role of developmental sophis- tication or complexity in the categorization and judgment of choice attributes. These competing frameworks can be distinguished by the type of task involved. In the developmental literature the experimental tasks required of the subjects generally involve abstract cognitive or perceptual skills. For example, subjects are often asked to sort stimuli on the basis of similarities. Greater differentiation (such as more categories) is predicted for those more experienced or advanced in the task. In the social judgment literature the tasks involve preference judgments, particularly of social or attitudinal stimuli, and the reverse is generally expected. Fewer categories are predicted for those more experienced or familiar with the issue.

The prediction of greater differentiation in the developmental literature on which the hypothesis in this study was based is generally confined to the perceptual/cognitive domain of meaning. Based on the works of Piaget, Gibson, and Werner, Flavell (1972) concludes that differentiation is among the most prevalent modes of developmental change. Conceptual development "involves the differentiation or articulation of previously unitary and undifferentiated cognitive items" (p. 300). This is thought to translate into the use of more attributes in making choices and greater discrimination (articulation) across levels of an attribute. Further. similar developmental hypotheses have been confirmed in the context of cognitive mapping where experience or familiarity represents the developmental continuum (Moore, 1979) and to a certain degree in recreation preference and choice research (Schreyer, 1982; Schreyer \& Beaulieu. 1986; Williams et al., 1989).

A similar prediction relates extreme response style in attitude measures (for example, the tendency of subjects to mark scaled responses at one or the other extreme) to cognitive complexity. Hamilton (1968) cites a number of studies indicating that extreme response style is strongly associated with undifferentiated cognitive structure (analogous to making fewer conceptual distinctions). An important confounding issue, and one that is particularly relevant to this study, is that the meaningfulness of stimuli to the individual increases the extreme response style. Thus, more involved subjects or those that are more familiar with the stimuli are perhaps more likely to exhibit an extreme response style.

In the research on social judgment (Petty \& Cacioppo, 1981; Sherif \& Hovland, 1961), the predictions about how persons will discriminate along a dimension are similarly related to ego involvement. The basic assumption of social judgment theory is that judgment involves discrimination and categorization of attitudinal stimuli. According to social judgment theory, an attitudinal dimension is composed of three regions or latitudes: positions that are acceptable, unacceptable, and noncommital. Research in social judgment has consistently demonstrated that the number of categories a person chooses to use varies inversely with the person's degree of involvement with the issue or object (such as its intrinsic importance, its personal meaning, or its significant personal consequences)(Petty \& Cacioppo. 1981). The explanation given is that involved subjects have wider latitudes of 
rejection. The person's own position on an attitude serves as a strong anchor resulting in positions close to the person's own position being lumped together (assimilated) and objectional levels lumped together with very little discrimination. The overall result is fewer categories for highly involved subjects.

In the present study, and the Park studies on which this was based (Park, 1978; Park \& Lessig, 1981). the judgment task takes on strong preferential dimensions (such as rating the degree of satisfaction). In fact, the method of having subjects describe the ranges of conditions that produce similar amounts of satisfaction is very similar to the methods developed in the social judgment literature in which subjects indicate ranges of values that are acceptable or unacceptable. Contrary to social judgment theory, however, Park himself (Park \& Lessig, 1981) predicted greater numbers of categories for more familiar subjects. In his study he found that women who were apparently similar in terms of ego involvement but who differed in familiarity with microwave ovens did not differ in number of distinctive categories identified within the various product dimensions considered.

Thus, from the social judgment perspective our findings are not surprising. High involvement (as measured in this instance by previous experience) results in fewer categories when judged in terms of differences in satisfaction. These findings do not conflict directly with the results of Schreyer and others in which the rating task was less "judgmental" (rating degrees of satisfaction) and more "conceptual" (identifying and sorting attributes).

The important issue appears to be understanding the direction and meaning of developmental differences in perceptions, attitudes, preferences. and the like. The literature offers some support that developmental differences will be stronger when the task is perceptual or conceptual. For example. Schreyer's (1982) river running motivation study and Schreyer and Beaulieu's (1986) wilderness attribute study found no differences in motive or setting attribute preferences, but did find differences in how specifically these motivations or attributes were described (perceived). Conceptual differences also emerge across developmental levels in the form of the structuring of items. Williams et al. (1989). when comparing factor structures for motivation items across three levels of experience, found that the number and complexity of factors was greater with greater experience. Further, when preference differences do appear, they are stronger or more frequent for setting attributes compared to motives for participation (Virden, 1986; Williams \& Huffman. 1986).

Making this distinction between cognitive/perceptual and attitude/preference judgments may be important for sorting out competing and confusing predictions regarding the role of experience in other recreationrelated behaviors. As a frame of reference, experience equips us with a greater awareness of alternative choices (for example, we perceive more "categories), but experience also leads us to judge the consequences of a particular choice in fewer but more definitive and "black and white" terms.
These apparently competing tendencies are manifest in the often confusing predictions about satisfaction, displacement, substitution, and conflict. Moreexperienced participants are thought to be more aware of opportunities available and to make more "informed" choices, but at the same time are more sensitive to negative environmental conditions and changes. are more likely to experience dissatisfaction and conflict, are more prone to be displaced, and vet are less likely to perceive substitutes available.

The social judgment interpretation of our findings suggests that future research in these areas must proceed with greater caution and give greater attention to the nature of the judgment tasks involved. The predictions of cognitive developmental theorists do not directly apply to preference data and attitude judgments, and developmental theorists have never claimed that subjects will always exhibit their highest level of perceptual or cognitive ability (Flavell, 1972). Strong evaluative judgment of ego-involved participants is likely to be more definitive (involve a few broad and discrete categories). More-experienced participants are capable of processing greater amounts of and more complex information, and thus capable of making and using more categories. But to the extent that these same participants are more ego-involved (that is, know what they want), they may at certain times and under certain judgment conditions make fewer categorical distinctions. Thus, with experience we perceive, categorize, and choose among ever more shades of gray. But when we choose, commit, and involve our egos, our evaluations tend to become more black and white.

\section{References}

Beaulieu. J. T.. \& Schreyer, R. (1985). Choices of wilderness environments-differences between real and hypothetical choice situations. In G. H. Stankey \& S. F. McCool (Compilers), Proceedings-symposium on recreation choice behavior (General Technical Report INT184, pp. 38-45). Ogden, UT: USDA Forest Service. Intermountain Research Station.

Bieri. J. (1966). Cognitive complexity and personality and development. In 0. Harvey (Ed.). Experience, structures, and adaptability (pp. 13-37). New York: Springer Publishing Co.

Brown. P. J., Driver. B. L.. \& McConnell, C. (1978). The opportunity spectrum concept and behavioral information in outdoor recreation resource supply inventories: Background and application. In Integrated inventories of renewable natural resources: Proceedings of the workshop (General Technical Report RM-55, pp. 73-84. Fort Collins. CO: USDA Forest Service. Rocky Mountain Forest and Range Experiment Station.

Brown. P. J., \& Haas. G. E. (1980). Wilderness recreation experiences: The Rawah case. Journal Of Leisure Research, 12(3), 221-241.

Bultena, G. L.. \& Field, D. R. (1980). Structural effects in National Parkgoing Leisure Studies, 3(3). 221-240.

Clark, R. N.. \& Downing. K. B. (1985). Why here and not there: The conditional nature of recreation choice. In G. H. Stankey \& S. F. McCool (Compilers). Proceedings-symposium on recreation choice behavior (General Technical Report INT-184. pp. 61-70). Ogden. UT: USDA Forest Service. Intermountain Research Station.

Clark, R. N., Stankey, G. H. (1979). The recreation opportunity spectrum: a framework for planning management and research (General Technical Report PNW-98). Portland, OR: USDA Forest Service, Pacific Southwest Forest and Range Experiment Station. 
Driver. B. L., \& Brown, P. J.(1978). The opportunity spectrum concept and behavioral information in outdoor recreation resource supply inventories: A rationale. In Integrated inirntories of resimable natural resources: Procedings of the workshop (General Technical ReportRM-55. pp. 24-31). Fort Collins. CO: L'SDA Forest Service, Rocky Mountain Forest and Range Experiment Station.

Driver. B. L., Brown. P. J., Stankey, (;. H.. \& Gregoire. T. G. (1985). The Ros planning sistem: Evolution. basic concepts. and research needed. Leisure Sciences, Y(3), 201.212

Driver. B. L.. \&.Knopf. R. C. (1977). Personality, outdoor recreation. and expected consequences. Enironment and Beharior.9(2),169- 193.

Feimer. N. R. (1983). Environmental perception and cognition in rural conlexts. In A.W: Childs \&.G. B. Melton (Eds.). Rural Psycholog (pp. 113-149). Nen Y'ork: Plenum Press.

Flavell, J. H. (1972). Analy sis of cognitive developmental sequences. Genetic Psychological .Monographs, 86. 279.350.

Gregoire. T. G.. \& Driver, B. L. (1987). Type It errors in leisure research. Journal of Leisure Research. $19(4), 261.272$.

Haas, G. E.. Driver. B. L.. \& Brown, P. J.(19\&0, August). Measuring nilderness recreation experiences. Paper presented at the Wilderness Psychology Conference. Durham, NH.

amilton. D. L. (1968). Personality altributes associated with extreme response style. Psychological Bulletin, 69, 192-203.

Hammitt, W. E.. \& McDonald, C. D. (1983). Past on-site experience and its relationship to managing river recreation resources. Forest Srience, 15 . 34-45.

Hendee, J.C., \& Roggenbuck.J.W:(1985). Wilderness-related education as a factor increasing demand for wilderness. In Intemational forest congress 1984: Forest resources managrmentthe influence of polin and low (pp. 273-278). Washington. DC: Societ) of American Foresters.

Knopf, R. C. (1983). Recreational needs and behavior in natural environments. In 1.Aliman \& ]. E. Wohluill (Eds.), Behaitor and the natural enivonment (Human Behavior and Environment, Vol. 6. pp. 205-240). Sew York: Plenum.

Krumpe. E. E.. \&.McLaughlin. W. J. (1982). A model of recreationists' decision making process In D. W: Lime (Ed.), Forest ad rier recreation: Research update (Miscellaneous Publication 18-1982, pp. 94-99). St. Paul, IIN:Agriculture Experiment Station.

Lew is-Beck. M. (1980). Applicd regression: A nintroduction. Beverl) Hills, CA: Sage Publications. Lieber. S. R.. Fesenmaier, D. R., \& Bristow, R. S. (1989). Recreation expenditures and op portunity theory: The case of Illinois. Journal of Leisure Research, 2l(2), 106-123.

Manfredo, ht. J.. Driver, B. L. \& Brown, P. J.(1983).Atest of concepts inherent in experience based setting management for outdoor recreation areas. Jounual of Leisure Research,15(3) 263-283.

McCool. S. F.. Stankey, G. H.. \& Clark, R. S. (1985). Choosing recreation settings: Processes fitudings, and research directions. In G. H. Stanke) \& S. F. MrCool (Compilers). Procred ings-symposium on recieation choice behavior (General Technical Report 1NT-184, pp. I-8). Ogden. UT: USDA Forest Service, Intermountain Research Station.

Moore. G. T. (1979). Knowing aboul environmental knowing: The current state of theor and research on environmental cognition. Entironment and Beflavior, II, 33-70.

Park, C. W. (1978). A conflicı resolution choice model. Journal of Consumer Research, 5, 124 137.

ark. C. W.. \& Lessig, V.P. (1977). Judgmental rules and stages of the familiarit) curve: Promotional implications. Journal of Adiertising, 6. IO- $\mathrm{t} 6$.

Park. C. W., \&-Lessig, V.P.(1981). Familiarity and itsimpact on consumer decision biases and heuristics. Journal of Consumer Research. b'(2). 223-230.

Petersun, G. L.. Dwyer, J. F.. \& Darragh, A. (1983). A behavioral urban recreation sire choice model. Leivure Scirnces, 6(I). 61-8I.
Peterson, G. L., Stynes, D. J., Rosenthal, D. H.. \& Dw yer. J. F. (1985). Substitution in recreation choice behavior. In G. H. Stankey \& S. F. McCool (Compilers), Proceedings-symposium on recreation choice behaizior (General Technical Report INT-184, pp. 19-30). Ogden, UT: I'SDA Forest Service. Intermountain Research Station.

Peul! , R. E., \&. Cacioppo. J. T. (1981). Atuitudes and persuasion: Classic and convemparay approaches. Dubuque, 1.4: WM. C. Brown Company Publishers.

Roggenbuck, J.W., \& Dakson. M. S. (1 979). Recreation experience preferences of wildeness and backrountn hikers. Linpublished report, Department of Forestri. Virginia Polytechnic Institute and State L'niversity. Blacksburg.

Schreyer, R. (1982). Experience level affects expectations for recreation participation. In D. W. Lime (Ed.), Forest and nier recreation: Research update (Miscellaneous Publication 18-1982. pp. 154-159). St. Paul. MS: Agriculture Experiment Station.

Schreyer, R.. \& Beaulieu. J. T. (1986). Attribute preferences for wildland recreation seltings. Journal of Leisure Research, 18(4), 231-247.

Schreyer. R., Knopf, R. C., \& Williams, D. R. (1985). Reconceptualizing the molive/environmentlink in recreation choice behavior. In G. H. Stankey \&. S. F. McConl (Compilers), Proceedings-symposium on recreation choice beharior (General Technical Report t NT-184, pp. 9-18). Ogden, CT: LSD.A Forest Service. Intermountain Research Station.

Schreyer, R.. \& Lime, D. W. (1984). A novice isn't necessarily a novice-the influence of experience use history on subjective perceptions of recreation participation. Leisure Sciences, 6(2), 131-149.

Schreyer, R., Lime, D. W., \& Williams, D. R. (1984). Characterizing the influence of past experience on recreation behavior. Journal of Leisure Research.J6(1), 34-50.

Schreyer, R.\& \& Roggenbuck. J. (1978). The influence of experience expectations on crowding perceptions and social-ps)chological carrying capacities. Lnisure Sciences.J(4), 373-394.

Schuster. E. G., \&-Zuuring, H. R. (1986). Quantifying the unquantifiable-or. have you stopped abusing measurement scales? Joumal of Forestr. 84(4), 25-30.

Scoll.W. A. (I 969). The structure of natural cognitions. Joumal of Personality and Social Psy chologi, 12(4), 261-278.

Sherif, M.. \&.Hovland, C. I. (1961). Social judgment: Assimiletion and contrast effects in communication and attitude change. Sew Haven, CT: Yale University Press.

V'irden, R. J. (1986). The effects of recreation specialization and motivation on the entironmental surver preferences of backcountry hikers. Unpublished doctoral dissertation, U'tah State University, Logan, UT.

Watson, A. E. (1983). An application of behavioral decision theon to recreation site selection. Unpublished doctoral dissertation, Department of Forestry, V'irginia Polytechnic Institule and State L'niversity, Blacksburg, VA.

Wesi, P. C. (1982). A nationwide test of the status group dinamics approach to outdoor recreation demand. Leisure Sciences, $5(1)$, I- 18.

Williams, D. R (1985). A developmental model of recreation choice behavior. In G. H. Stankey \& S. F.McCool (Compilers), Praceedings-sympasium on recreation choicc beharior (General Technical ReportINT. 184, pp. 31-38). Ogden, UT: USDA Forest Service, Intermountain Research Station.

Williams, D. R.. \&.Huffnan.M. G. (1986). Recreation specialization as a facior in backcountry trail choice. In R. C. Lucas (Compiler), Proccedings-national wilderness research conference: Currentresearch (General Technical Report INT-212.pp. 339-344). Ogden. UT: USDA Forest Service. Intermountain Research Station.

Williams, D. R.. \& Knopf, R. C. (1985). In search of the primitive-urban continuum-the dimensional structure of outdoor recreation settings. Encironment and Behavior, $J 7(3)$ $351 \cdot 370$ 
Williams. D. R.. Schreyer. R.. \& Knopf. R. C. (1989). The effect of experience use history on the multidimensional structure of motivations to participate in leisure activities. Journal of Leisure Research. 22(I), 36-X.

Received May 1, 1989

Revision Accepted May 1, 1990 